\title{
NARRATIVAS DE PROFESSORES DE SURDOS SOBRE A EJA NO MUNICÍPIO DE PORTO ALEGRE/RS
}

\author{
NARRATIVE OF DEAF TEACHERS ON EJA IN PORTO ALEGRE CITY/RS \\ NARRATIVA DE MAESTROS DE SORDOS SOBRE A EJA EN LA CIUDAD DE \\ PORTO ALEGRE/RS
}

Ana Luiza Paganelli Caldas Professora Mestre da Universidade Federal do Rio Grande do Sul (UFRGS). anacrespa2012@gmail.com

\begin{abstract}
RESUMO: Este artigo busca conhecer e analisar as narrativas de quatro professores de educação de surdos que atuaram no Centro Municipal de Educação do Trabalhador Paulo Freire, de Porto Alegre, com jovens e adultos surdos, alunos que hoje são atendidos na Escola Municipal de Ensino Fundamental de Surdos Bilíngue Salomão Watnick. Sobre o processo de educação desses alunos iniciarei com uma breve história sobre a Educação de Jovens e Adultos no Centro Municipal de Educação do Trabalhador Paulo Freire e a migração para a escola municipal bilíngue Salomão Watnick. Com objetivo de esclarecer como é a educação de adultos surdos investiguei, através das narrativas, a experiência dos professores dos surdos na EJA procurando explicar o conceito de educação bilíngue, bem como a importância desta educação para o surdo e quais são os principais desafios e conquistas desta modalidade, finalizando com argumentação em favor da Libras enquanto língua de formação pedagógica para surdos. PALAVRAS-CHAVE: Educação de Surdos. Educação de Jovens e Adultos Surdos. Narrativas de professores.
\end{abstract}

ABSTRACT: This article seeks to understand and analyze the narratives of four deaf education teachers that worked at the Municipal Center of Paulo Freire Worker Education of Porto Alegre, with young deaf adults, students today are treated at Municipal Elementary School of the Deaf Solomon Watnick bilingual. About the process of education of these students shall begin with a brief history of the Youth and Adult Education at the Municipal Center of Paulo Freire Worker Education and migration to bilingual public school Solomon Watnick. In order to clarify how the education of deaf adults investigated through the narrative, the experience of deaf teachers in adult education seeking to explain the concept of bilingual education, and the importance of education for the deaf and what are the main challenges and achievements this mode, ending with arguments in favor of pounds as a language teacher training for the deaf.

KEYWORDS: Deaf Education. Education Youth and Adult Deaf. Narratives teachers.

RESUMEN: Este artículo busca entender y analizar las narrativas de cuatro maestros de educación de sordos que trabajaran en el Centro Municipal del Trabajador Paulo Freire, en Porto Alegre, con jóvenes y adultos sordos, estudiantes que hoy son atendidos en la Escuela Municipal Primaria de Sordos Bilingüe Salomón Watnick. Sobre el proceso de la educación de estos estudiantes empezaré con una breve historia sobre la educación de jóvenes y adultos en el Centro Municipal de Educación del Trabajador Paulo Freire y la migración a la escuela pública bilingüe Salomón Watnick. Con lo objetivo de aclarar como es la educación de adultos sordos investigué, a través de las narrativas, la experiencia de los maestros de los sordos en la EJA, tratando de explicar el concepto de educación bilingüe, así como la importancia de la educación para sordos y cuáles son los principales retos y logros de esta modalidad, terminando con argumentos a favor de la Libras mientras lengua de formación pedagógica para sordos. PALABRAS CLAVE: Educación de Sordos. Educación de Jóvenes y Adultos Sordos. Narrativas de Maestros.

$\overline{\text { Artigo recebido em maio de } 2016}$

Aprovado em julho de 2016 


\section{1| INTRODUÇÃO}

Sou professora surda com Magistério, graduada em Pedagogia, com pós na área da educação e afirmo que frequentar a educação básica na idade apropriada transformou minha vida e possibilitou de maneira mais segura o meu ingresso no ensino superior. No entanto, toda minha educação foi em escola de ouvintes e sem intérpretes. Não havia leis que tratassem deste assunto na época. Mas com muito auxílio da família e de colegas, finalizei todas as etapas.

A escola deve ser um elemento transformador. A isso, acrescentaríamos: deve sê-lo de modo especial para o surdo, mais do que qualquer outra criança ouvinte, pois temos que admitir o seu universo, mas transformar a sua deficiência em eficiência. (ESCOLA MUNICIPAL DE ENSINO FUNDAMENTAL DE SURDOS BILÍNGUE SALOMÃO WATNICK, [200-]).

A escola de que trato na citação é uma conquista da comunidade surda, fruto do movimento social engajado em busca das transformações necessárias na educação dos surdos, em Porto Alegre. Hoje com a experiência adquirida na educação de surdos verifico que sempre existem dificuldades para serem superadas, especialmente na modalidade da educação de jovens e adultos surdos.

Trabalhei no Centro Municipal de Educação do Trabalhador Paulo Freire (CMET), de 2008 até 2012, assim como na Escola Salomão Watnick de 2008 até 2010, voltando em 2013 e 2014. A criação desta escola foi importante porque a luta da comunidade surda procurou a construção de uma escola que pudesse atender a suas diferenças linguísticas e culturais. Nesse mesmo ano fui convidada para participar do curso de extensão oferecido pela Faculdade de Educação da UFRGS Memórias, narrativas e experiências docentes na educação de surdos, o qual auxiliou muito na minha pesquisa com narrativas. Participei narrando minha experiência de vida e início da escolarização, e como me tornei professora surda.

Observei que os professores concursados que atuavam na turma de surdos no CMET Paulo Freire eram qualificados e experientes na área da educação para surdos com fluência na Libras. Lecionava na turma da terceira totalidade ${ }^{1}$ com jovens e adultos surdos que possuíam entre 17 e 78 anos de idade. Percebi que meus alunos gostavam muito da relação comigo, professora surda. Eles se impressionaram muito porque eu me expressei com fluência em Libras, mas apesar da comunicação foi um desafio para mim a experiência na educação de jovens surdos porque os alunos vinham de uma realidade com pouco ou nenhum contato com educação escolar. Trabalhava as imagens visuais das relações em vocabulários e estruturas frasais básicas, é muito importante revisar e repetir para incentivar a memória de cada aluno. Perguntava aos alunos se eu conseguia responder seus questionamentos. Dei muitas informações para eles entenderem o que acontecia na mídia. Gostava cada vez mais e na Educação de Jovens e Adultos surdos aprendi muitas coisas e convivi quatro anos com o grupo do CMET. Fui coordenadora pedagógica em 2010. As colegas tinham oportunidade de aprender melhor com o contato mais próximo da comunicação em Libras, como eu sou surda necessitavam se relacionar diretamente em Libras. Elas gostavam e eu também. Desafiei muito a elas e também os alunos da EJA.

\footnotetext{
${ }^{1}$ As totalidades de conhecimento não representam etapas estanques, nem sequencia lineares, de tal forma que não necessariamente se precise partir de uma para chegar na outra. Trabalhamos de forma interdisciplinar, não priorizamos conteúdos por etapas, trabalhamos com grandes temas e escolhemos conceitos. Os conteúdos, portanto, perdem seu antigo status e ficam a serviço desses conceitos, e são liberados para serem desenvolvidos em qualquer Totalidade. Para não perdermos os rituais de passagem, denominamos T1, T2 e T3 para o trabalho inicial e T4, T5 e T6 para o final do ensino fundamental. (DETANICO, [201-]).
} 
Durante minha experiência percebi que muitos adultos surdos não sabiam Libras, se comunicavam por gestos próprios e não sabiam ler e escrever Português. Eu também tenho muitas dificuldades em português, ainda hoje é difícil como segunda língua. Mas imagine o surdo adulto sem saber; como faz para se comunicar com o mundo ouvinte quando quer um pão na padaria, por exemplo? Por gestos, certo! Mas como se comunicar para conseguir emprego e autonomia social?

Com estas inquietações procurei entrevistar os professores que deram início às atividades de educação de surdos na modalidade EJA no município de Porto Alegre para que a partir das narrativas construídas possamos refletir e dar continuidade ao debate acrescentando qualidade nas experiências educativas. Portanto, foram convidados para fazer a entrevista quatro professores que lecionaram nas primeiras turmas de surdos no ensino municipal de Porto Alegre, sendo três ouvintes e um surdo. Todos são educadores, três são professores universitários e uma é professora na escola bilíngue da rede municipal. Aqui aparecem seus nomes fictícios.

\begin{tabular}{|l|l|}
\hline Leila Motta (ouvinte) & $\begin{array}{l}\text { Doutora em Educação pela UFRGS, com experiência na educação de } \\
\text { surdos desde 1992. }\end{array}$ \\
\hline Luana Cruz (ouvinte) & $\begin{array}{l}\text { Doutora em Linguística e Letras pela PUCRS, com experiência na } \\
\text { educação de surdos desde 1992. }\end{array}$ \\
\hline Tânia Maciel (ouvinte) & Professora com experiência na educação de surdos desde 1996. \\
\hline Walter Ferraz (surdo) & $\begin{array}{l}\text { Doutor em Educação pela UFRGS, com experiência na educação de } \\
\text { surdos desde 1988. }\end{array}$ \\
\hline
\end{tabular}

As entrevistas foram realizadas por e-mail e para tecer as narrativas deste artigo foram realizadas as seguintes perguntas:

a) Como surgiu a educação de jovens e adultos surdos na municipal de Porto Alegre?

b) Como ocorre o processo da aprendizagem da Libras pelos alunos que chegam na escola já jovens ou adultos e não usam essa língua?

c) Como é a proposta de educação da escola bilíngue e a comunicação entre professores ouvintes e alunos surdos?

d) Como foi o processo de mudanças de espaços da EJA, que iniciou no CMET e hoje acontece na escola bilíngue?

e) Quais os principais desafios da EJA para surdos na escola?

f) E quais as conquistas?

Iniciarei apontando uma análise das narrativas no que se refere à experiência docente de professores da Educação de Jovens e Adultos Surdos, justificando também a escolha do trabalho com narrativas. Num segundo momento partirei para a narrativa da história da EJA para surdos na rede municipal de Porto Alegre apontando fatos e datas conforme citaram os entrevistados. $\mathrm{Na}$ terceira parte constam breves apontamentos sobre a EJA no contexto da educação bilíngue, considerando a importância da Libras como primeira língua de comunicação e de ensino. A quarta e última parte traz a narrativa sobre o reconhecimento da Libras enquanto língua da formação pedagógica e cultural da comunidade surda. 


\section{2 | NARRATIVAS E ESTUDOS CULTURAIS: A EXPERIÊNCIA ESCOLAR DA EJA PARA SURDOS}

A experiência escolar da EJA para surdos é fruto de uma luta histórica organizada pela comunidade surda, mas é também consequência do momento da história em que vive a sociedade, onde as "lentes" dos Estudos Culturais e dos Estudos Surdos constituem uma ressignificação no campo pedagógico, proporcionando assim, que temas como cultura e identidade sejam pesquisados, possibilitando a construção de novos conhecimentos, os quais, anteriormente, eram rejeitados.

[...] as "lentes" dos EC parece que vêm possibilitando entender de forma diferente, mais ampla, mais complexa e plurifacetada a própria educação, os sujeitos que ela envolve, as fronteiras. De certa maneira, pode-se dizer que os Estudos Culturais em Educação constituem uma ressignificação e/ou uma forma de abordagem do campo pedagógico em que questões como cultura, identidade, discurso e representação passam a ocupar, de forma articulada, o primeiro plano da cena pedagógica. (COSTA; SILVEIRA; SOMMER, 2003, p. 54).

A educação de surdos é uma dessas formas diferentes que os Estudos Culturais em Educação trazem à tona na sociedade atual fortalecendo a cultura, a identidade, o discurso e a representação surda na constituição do sujeito surdo. A escolha em trabalhar com narrativas é importante por ser uma forma discursiva de entrevista em que se abordam histórias de vida, onde, por meio destas, podemos identificar as histórias das sociedades. Utilizei as narrativas como método para coletar dados e detalhes das experiências escolares de professores que atuam na educação de surdos na rede municipal de Porto Alegre, no Centro Municipal de Educação dos Trabalhadores (CMET) Paulo Freire, na modalidade de educação de jovens e adultos.

\footnotetext{
Através de uma narrativa, as pessoas lembram do que aconteceu, colocam a experiência em uma sequência, encontram possíveis explicações para isso, e jogam com a cadeia de acontecimentos que constroem a vida individual e social. [...] sua ideia básica é reconstruir acontecimentos sociais a partir da perspectiva dos informantes, tão diretamente quanto possível. (JOVCHELOVITCH; BAUER, 2002, p. 91 e 93).
}

Por essa questão de reconstrução dos acontecimentos sociais é que os Estudos Culturais complementam a teoria deste estudo, pois frequentemente fazem uso das narrativas por se tratarem de um "conjunto de abordagens, problematizações e reflexões" (COSTA; SILVEIRA; SOMMER, 2003, p. 40) acerca de assuntos da sociedade. Na articulação dos Estudos Culturais com os Estudos Surdos temos o cruzamento entre diferentes disciplinas, isto é, de um lugar de encontro entre diferentes grupos e movimentos intelectuais, que acabam por intercambiar pontos de vista e trocas de inspirações e experiências que viabilizam a concretização de objetivos.

Abordagens sobre questões de metodologia e política na escolarização dos vários níveis, discussões sobre relações de poder no currículo e na sala de aula, bem como contribuições aos debates sobre infância, cidadania, identidade nacional, pedagogias culturais na pós-modernidade, a cultura do "outro", raça, gênero e etnia no capitalismo neoliberal, efeitos da globalização e do neoliberalismo na educação, o combate à contínua colonização dos saberes e das relações sociais nas escolas emergem das várias propostas formuladas. (COSTA; SILVEIRA; SOMMER, 2003, p. 53). 
Nessa perspectiva, essa nova abordagem de análise tem possibilitado que culturas antes renegadas a um papel periférico como, por exemplo, a questão de gênero, a cultura surda, dos índios e dos africanos, os quais emergiram através da questão das identidades, assumissem um papel que até então não tinham acesso. A incorporação nas escolas, através de legislação específica, das disciplinas de Libras e Estudos da História Africana e Indígena são exemplos dessa nova concepção pedagógica a qual assistimos. É um momento novo, como podemos ver os seus reflexos através da citação abaixo:

\footnotetext{
Nessa direção, projetos de pesquisa integrados ou individuais, trabalhos de iniciação científica, dissertações de mestrado e teses de doutorado têm sido produzidos nos últimos cinco anos, em especial no âmbito do Programa de Pós-Graduação em Educação da Universidade Federal do Rio Grande do Sul, na linha de pesquisa Estudos Culturais em Educação e em outros grupos que partilham de seu direcionamento teórico. (COSTA; SILVEIRA; SOMMER, 2003, p. 56)
}

Observa-se que a obrigatoriedade das temáticas até então ausentes da escola, como a LIBRAS, possibilitou um reforço no que diz respeito a pesquisas sobre a temática. A professora Luana Cruz, uma das entrevistadas, que foi professora dos surdos no antigo CMET e hoje em dia é professora da UFRGS; diz que a EJA para surdos "aconteceu porque alguns surdos questionavam por que não havia turmas de adultos surdos". Esta professora, assim como os demais professores entrevistados, trabalharam nas turmas inicias da EJA para surdos. No início era apenas uma única turma e não havia prédio próprio, nem concursos. Os professores que assumiram essa turma foram os que já trabalhavam na Prefeitura e se identificavam com a luta dos surdos por uma educação de qualidade.

Conforme relata Walter Ferraz, primeiro professor surdo da escola e atualmente trabalhando na UFSM, a criação desta turma na capital atraiu o interesse de alunos surdos de outras cidades, com o objetivo de matricularem-se nesta escola, além de jovens e adultos que não sabiam LIBRAS, também idosos e surdos com outras deficiências e síndromes associadas. Neste sentido, a professora Leila Motta, que hoje também trabalha na UFRGS, afirma que "o encontro com outros surdos adultos é o que impulsiona a aprendizagem da língua”. Estudos de Fernando Cesar Capovilla (2012a) dizem que uma educação humanizada e eficaz deve respeitar o idioma e a cultura. A pesquisa dele diz que "os alunos surdos se desenvolvem mais e melhor em escolas especiais para surdos [...], ao passo que os alunos com deficiência auditiva se desenvolvem melhor em escolas comuns em regime de inclusão." Este autor diferencia os educandos que possuem deficiência auditiva, ou seja, aqueles que ouvem parcialmente, dos educandos surdos, já que a escola em regime de inclusão não trabalha com a Libras enquanto língua materna; ao passo que a escola bilíngüe utiliza a Libras enquanto língua materna. O estudo foi realizado com crianças, mas podemos fazer uma analogia com adultos ao passo que existe a identificação da surdez para se orientarem os projetos didáticos, sendo as aulas ministradas em Libras.

Nossos estudos e análises sobre a educação de surdos possibilitaram a compreensão que ainda faltam informações aos alunos surdos. Não havia ensino sobre educação sexual, questão muito necessária já que são jovens e adultos. A maioria dos surdos pouco conhece sobre conteúdos escolares e tem problemas de comunicação com a sociedade ouvinte e precisam mais informações para evitar doenças sexuais, diabetes, colesterol, hipertensão, etc. Considerando tal análise observa-se que existem deficiências no contexto das disciplinas, no que concerne ao ensino de pessoas surdas. Torna-se assim necessário que tais assuntos sejam trabalhados como parâmetros para atividades ricas de conteúdo para EJA de surdos. 


\section{3 | HISTÓRIA DA EJA DE SURDOS EM PORTO ALEGRE}

Apesar da Prefeitura de Porto Alegre possuir muitas escolas de educação infantil e fundamental, até o ano de 1998 não tinha atendimento à comunidade surda, nem para crianças, nem para adultos.

A educação de jovens e adultos surdos surgiu, efetivamente, somente em 1998, sendo que o ensino fundamental na perspectiva da educação bilíngue só foi possível em 2008, com a criação da Escola Municipal de Ensino Fundamental de Surdos Bilíngue Salomão Watnick.

O entrevistado Walter Ferraz narra que o Serviço de Educação de Jovens e Adultos (SEJA) "foi criado na primeira gestão da Administração Popular, em 1989". Porém, "somente em 1997 criou-se o Centro Municipal de Educação dos Trabalhadores (CMET). [...] Em maio de 1998, surgiu a primeira turma de alunos surdos do CMET, através do movimento da comunidade dos surdos junto ao Orçamento Participativo". Esse fato é citado por todos os entrevistados. A SEJA funcionou muitos anos sem prédio próprio, circulando em diferentes espaços cedidos.

A entrevistada Luana Cruz, que foi uma das primeira professoras do CMET, nos conta que ingressou no magistério público em 1992 e não tinha escola de surdos na rede municipal. Através dos movimentos dos surdos pela educação no Orçamento Participativo (OP) foi possível conseguir um espaço de sala de aula para jovens e adultos surdos. Os adultos surdos ficaram felizes em retomar os estudos, pois procuravam escolas por muito tempo e estas não tinham o ensino adequado para eles. A entrevistada, Tânia Maciel, professora da rede municipal, acrescenta que a modalidade EJA na escola Salomão Watnick foi oferecida a partir de 2013.

Em 1998, foi implantada a primeira turma de surdos no CMET com 15 alunos. A diretora era a professora Mara Moreira, que abriu as portas do CMET para esse projeto. Leila Motta e Luana Cruz foram as primeiras professoras e foi ampliado o trabalho com mais uma turma. As turmas iniciais correspondiam a três totalidades de conhecimento dos anos iniciais do ensino fundamental, com um professor ouvinte, com conhecimento em língua de sinais.

Walter Ferraz ingressou no magistério público em 1999, sendo o primeiro professor surdo de Porto Alegre, iniciando sua carreira no CMET junto com as colegas Leila e Luana, que já atuavam na escola. A professora Tânia Maciel entrou depois e ainda continua na escola bilíngue.

Em 1999, fica estabelecida a possibilidade de sonhar coisas impossíveis e de caminhar livremente em direção aos sonhos. Foi construído no CMET um novo regimento contendo as turmas de surdos. O professor surdo Walter Ferraz começou a trabalhar na escola. Com sua presença começa-se a pensar na necessidade de intérprete no CMET e no Conselho Escolar.

$\mathrm{O}$ ano de 1999 culminou com um contingente de mais de 40 alunos surdos organizados nas três totalidades iniciais, atendidos por um professor em cada totalidade, sendo um professor surdo e dois professores ouvintes com conhecimento da Língua de Sinais. Para o início do ano 2000, a comunidade surda continua a sua luta no Orçamento Participativo (OP), dando continuidade ao trabalho com a formação da Totalidade 4, sendo nomeados professores para cada disciplina, que, por não conhecerem a Língua de Sinais, eram acompanhados por intérpretes de Libras em tempo integral. Ressalta-se que se manteve garantido o acesso e a permanência de alunos surdos em turmas específicas de surdos desenvolvendo a cultura, multiplicando o espaço para as "vozes" que refletem sobre os problemas da sociedade e buscam soluções. É isto que a escola de surdos pretende, introduzir o sujeito no convívio social.

Em 2001, a professora Tânia Maciel inicia o trabalho com surdos no CMET. Já estava constituído enquanto projeto de escola, incluindo a ampliação das turmas para as Totalidades 4 e 5 , sendo a Totalidade 6 prevista para o inicio do ano letivo de 2002. As turmas somavam um número aproximado de 70 alunos, havendo professores por Totalidades e por área de conhecimento. E em 2002 iniciava turmas de educação em artes, inglês e demais. 


\section{NARRATIVAS DE PROFESSORES DE SURDOS | Ana Luiza Paganelli Caldas}

Em 2007, o Prefeito José Fogaça inaugura a primeira escola de surdos da Capital. O professor surdo Walter Ferraz escolheu um nome muito significativo para batizar a escola: Salomão Watnick. Uma marca histórica para a comunidade surda de Porto Alegre, Watnick foi o responsável pela fundação da Associação de Surdos na casa do casal surdo Watnick. Relembrar um nome importante na homenagem significa tornar presente a história dos surdos.

Muitos surdos não tinham formação e precisavam terminar o ensino fundamental e o médio com o objetivo de conseguir trabalho.

Nos anos de 2012 e 2013 a UFRGS desenvolveu, em parceria com a escola, projetos de formação com os professores em horário de reunião pedagógica. Em um dos Projetos, o Projeto Jogos Lógicos, os professores vivenciaram uma sequência de jogos de tabuleiro, e a experiência vivenciada no projeto de formação de professores foi aplicada com a turma de alunos da escola.

Nos dias atuais, a Escola Bilíngue Salomão Watnick atende a EJA nos turnos da manhã e noite, sendo os alunos jovens trabalhadores a partir de 15 (quinze) anos, com aproximadamente 30 (trinta) alunos, entre os quais também estão matriculados alunos com deficiências físicas, mentais, e visuais associadas à surdez.

\section{4| A EJA NO CONTEXTO DA EDUCAÇÃO BILÍNGUE}

Novamente nos referimos às pesquisas de Fernando Cesar Capovilla (2012b) na área da educação dos surdos porque estas também enfatizam a educação em língua materna, acompanhada do português escrito, mas inserido numa comunidade linguística sinalizadora.

\footnotetext{
As escolas bilíngues são aquelas onde a língua de instrução é a Libras e a Língua Portuguesa é ensinada como segunda língua, após a aquisição da primeira língua; essas escolas se instalam em espaços arquitetônicos próprios e nelas devem atuar professores bilíngues, sem mediação de intérpretes na relação professor-aluno e sem a utilização do português sinalizado. (BRASIL, 2014, p. 4).
}

Dessa forma, a escola bilíngüe é o espaço que respeita a diferença linguística entre surdos e ouvintes e possibilita que o surdo aprenda os conteúdos na sua língua materna: a LIBRAS.

O professor surdo Walter Ferraz destaca que "a educação no Centro se caracteriza pelos espaços e tempos diferenciados de construção de conhecimentos em todas as atividades". Atendendo à organização do currículo por Totalidades, a Libras facilita a aprendizagem e o contato dos pares surdos, auxilia na construção da identidade surda, adquirindo experiência visual e cultural, já que muitos educandos nunca frequentaram a escola, não conhecem a Libras e possuíam sinais próprios quando chegavam ao CMET, conforme explicam os entrevistados.

Luana Cruz, professora universitária, relata que inicialmente eram ministradas aulas de Libras desenvolvendo "uma proposta pedagógica articulada com a Educação de Jovens e Adultos da Prefeitura Municipal de Porto Alegre". Havia duas salas para as Totalidades 1 (um) e 2 (dois). Com o tempo as salas foram aumentando até conseguir atingir as 6 (seis) Totalidades da EJA. Walter Ferraz, professor universitário, também destaca que em 2008, com a criação da escola para surdos, foi reelaborado o Projeto Político Pedagógico colocando como lema "o direito à educação para todos". Tânia Maciel cita que a disciplina de Língua de Sinais está presente em "todas as etapas do ensino fundamental na modalidade EJA". E Leila Motta, professora universitária, completa: "A língua de sinais em contextos bilíngues é a língua de comunicação e de ensino, sendo a língua portuguesa compreendida como segunda língua na modalidade escrita [...]". 


\section{NARRATIVAS DE PROFESSORES DE SURDOS | Ana Luiza Paganelli Caldas}

Chamamos a atenção para o fato que precisamos compreender melhor o que significa o Bilinguismo. Não podemos tratar do assunto superficialmente, já que a vida de pessoas e mesmo a sua cultura estão em jogo. O Bilinguismo para os surdos é diferente daquele aplicado aos ouvintes. Para o ouvinte é mais um meio de aquisição de informações, duas línguas orais ou uma língua oral e outra sinalizada. Para o surdo é um meio de comunicação interpessoal e uma língua escrita. Recebe naturalmente apenas uma língua durante o desenvolvimento da linguagem inserido na comunidade linguística sinalizadora. Os surdos que tem uma identidade surda constroem sua autonomia, sua independência, seus valores, participação social, convivência e passam a ser um agente mais ativo na sociedade. Nas escolas de surdos, no contato com surdos adultos, os alunos e alunas surdos têm favorecido seu aspecto cultural, reconhecem e valorizam a história brasileira dos surdos, mesmo que os professores sejam ouvintes, por que a comunicação é em Libras.

Ana Claudia Balieiro Lodi (2013, p. 61) afirma que:

[...] há um embate de natureza ideológica entre os sentidos de educação bilíngue para surdos e de inclusão construídos na teia interdiscursiva constitutiva da Política Nacional de Educação Especial na Perspectiva da Educação Inclusiva e no Decreto 5.626/05.

Essa afirmativa vem sendo desenvolvida ao longo de debates sobre os diferentes aspectos e paradigmas da educação dos surdos. A autora traz à luz uma discussão sobre a educação bilíngue e as propostas das práticas inclusivas. Dessa forma, a ideia é que a inclusão de surdos na rede regular de ensino, mesmo havendo práticas socializantes e desafiadoras, como é a visão da PNEE, na verdade colabora como um mecanismo que busca "perpetuar a ideologia dominante de apagamento da diferença linguística-social e a imposição da língua portuguesa nos processos educacionais [...]" (LODI, 2013, p. 58). Defendendo, assim, que tais práticas inclusivas acabam por excluir as pessoas surdas dos processos educacionais e sociais, já que o aluno surdo não é ensinado na sua língua que é a Libras, forçando a oralização e a aquisição do entendimento do português. Torna-se assim importante que se faça a seguinte reflexão: como o surdo pode ser alfabetizado em português como primeira língua se ele não conhece o som das letras? Seu mundo é dos gestos primeiramente. É através dos gestos que o surdo entende a palavra. Do mesmo modo, é igual na Educação de Jovens e Adultos, a Libras é língua materna e o ensino deve ser priorizado em sua primeira língua para que possa adquirir autonomia para aprender português. A dinâmica de aula é diferente do ouvinte onde a professora ensina o som das letras para formar sílabas, e depois palavras. Primeiro aprende em Libras, depois escreve. A memória do surdo é visual; não sonora.

\section{5 | O RECONHECIMENTO DA LIBRAS ENQUANTO LÍNGUA DA FORMAÇÃO PEDAGÓGICA}

Considera-se a língua como um sistema social, que se constrói coletivamente e, por esta razão, os surdos precisam estar entre seus pares. A Língua de Sinais Brasileira foi oficializada através da Lei Federal 10.436, de 24 de abril de 2012, que a reconhece como meio legal de comunicação e expressão.

[...] as línguas de sinais nunca haviam sido vistas pela academia e pela sociedade como línguas naturais, com o mesmo estatuto das línguas orais [...] A educação bilíngue de surdos está marcada por traços da cultura surda, que precisam estar imersos nela, pois integram-na e são traços inseparáveis da educação bilíngue. Se a cultura surda não estiver inserida no ambiente educacional, os surdos dificilmente terão acesso à educação plena como lhes é de direito e acabam por abandonar a escola. (BRASIL, 2014, p. 8 e 13). 
A identificação com outras pessoas surdas favorece o sentimento de pertencimento a um grupo, o que possibilita criar novos significados dos espaços pedagógicos. A entrevistada Tânia Maciel afirma a importância de criar "elos comunitários que dialogam com os movimentos sociais, políticos e culturais que tem uma existência independente da escola", quer dizer que a comunidade surda extrapola os muros da escola necessitando respeito no uso de sua língua no convívio social.

Luana Cruz afirma que "trazer outras possibilidades de ensino e de trabalho com a educação de surdos requeria uma localização política do discurso educacional, com base na diferença linguística e cultural. Foi isso que realizamos em parceria com a comunidade surda". Pensar uma escola que agisse de forma diferente, que pensasse como o surdo, que pensasse em Libras, que transformasse o português em Libras.

Tânia Maciel diz que "o balizador fundamental da escola é atender aos alunos surdos, garantindo a aprendizagem em sua língua natural [...] considerando as diferenças linguísticas das pessoas surdas e ouvintes". Isto porque na escola bilíngue os professores ouvintes comunicam-se em Libras respeitando as diferenças linguísticas.

A entrevistada comenta ainda que:

Alunos Surdos, Surdos maiores de quinze anos, Surdos trabalhadores, Surdos jovens em busca do conhecimento/certificado para ingressar no mundo do trabalho, Surdos idosos, Surdos com deficiências associadas, Surdos com doença mental, adultos e jovens Surdos sem escolarização. Muitos destes alunos chegam sem terem adquirido a língua de sinais estruturada, cabendo à escola o trabalho de construção/resgate da identidade surda, da língua de sinais, enfim, da construção do sujeito surdo. (Tânia Maciel, entrevistada).

Leila Motta afirma que o "maior desafio é aproximar-se da discussão da Educação de Jovens e Adultos, não infantilizando metodologias e processos educativos". Ou seja, as metodologias de ensino e aprendizagem para alfabetização de jovens e adultos não podem se comparar às mesmas utilizadas na alfabetização de crianças.

O movimento surdo fortalecido lutou pela oficialização da Língua Brasileira de Sinais e, segundo os entrevistados, a maior conquista em Porto Alegre foi a criação da Escola Municipal de Educação Bilíngue. No entanto, conforme Thoma e Klein (2010, p. 13) nas últimas décadas, "as pautas da comunidade surda vêm-se reconfigurando" em relação às políticas educacionais porque tem diferenças entre escola inclusiva e escola de surdos. Enquanto a escola inclusiva necessita ter intérprete de Libras e não tem como ensinar o conteúdo diretamente em Libras para o aluno surdo, além disto, existem pouquíssimos profissionais habilitados e preparados para lecionar aos surdos na escola regular. A escola de surdos necessita indispensavelmente a educação com formação bilíngue, isto é, o conteúdo é ensinado em Libras diretamente entre professores e alunos, e o português é aprendido através da Libras.

A esse respeito Capovilla (2012a) cita que:

A escola especial constitui o foro especializado em desenvolver competências cognitivas e linguísticas no alunado surdo; ao passo que a escola comum em regime de inclusão constitui o campo de provas para retroalimentar a educação especial, garantindo que ela se esforce em instalar no alunado as competências requeridas para que a inclusão seja realmente bem sucedida na prática, e não apenas uma carta de boas intenções. [...] A importância da educação ministrada em Libras por professores sinalizadores fluentes em meio a colegas também surdos é tão maior quanto mais jovem a criança, e quanto maiores o grau da perda auditiva e a precocidade dessa perda auditiva. 


\section{NARRATIVAS DE PROFESSORES DE SURDOS | Ana Luiza Paganelli Caldas}

Nesse sentido, penso que é muito importante estimular precocemente o bebê surdo a aprender e ler a linguagem visual entre Libras e imagens (ilustrações, revistas, literaturas, fotos, figuras) para comunicar os questionamentos com expressão facial desde criança. Com um ano ou dois de idade brincar em contato com objetos e coisas e impulsionar a conversa para estimular a sua imaginação do mundo, criar e contar histórias. Também é necessário incentivar a família com o contato e a comunicação fundamental em Libras para que a criança surda tenha a possibilidade de aprender entre Libras e leitura e escrita de Português. Quando os pais não sabem ou não aceitam, perdem muito tempo da educação de seus filhos surdos, pois se aceitassem essa condição ficaria mais fácil e rápido a comunicação e o aprendizado.

Thoma e Klein (2010, p. 119) relatam que na pesquisa realizada durante o curso de extensão Memórias, Narrativas e Experiências Docentes na Educação de Surdos, as experiências escolares narradas pelas participantes "são resultados muito mais de esforços isolados do que proporcionados por políticas educacionais e linguísticas que tenham garantido sua permanência na escola." E ainda acrescenta que:

Ficaram evidentes na pesquisa a inexistência do profissional intérprete de língua de sinais nesses espaços escolares e a frágil formação dos professores, que indica a pouca fluência ou o desconhecimento da língua de sinais para se comunicar com os alunos surdos. (THOMA; KLEIN, 2010, p. 121).

A Libras, enquanto língua de formação pedagógica e cultural é a educação que nós surdos queremos. Enfatizamos que a grande questão é que a escola de inclusão de ensino regular não está preparada para atender nem crianças, nem jovens tampouco adultos surdos, mas principalmente surdos com deficiências associadas, porque não têm profissionais habilitados na Libras, nem materiais pedagógicos suficientes e apropriados. Na própria escola bilíngue torna-se indispensável a presença de professores surdos efetivados em seu quadro docente.

O ideal seria uma paridade entre professores surdos e ouvintes e também o aumento do número de escolas de surdos bilíngues, para que uma maior parcela da população surda possa continuar seus estudos até a faculdade, habilitar e qualificar através da formação continuada profissionais das diferentes áreas da educação, ou seja, profissionais que atuam nas áreas de biologia, ciências, matemática, geografia, história e química.

\section{6| CONSIDERAÇÕES FINAIS}

Os alunos da EJA tem dificuldade de conhecer a gramática de Libras, a história de Libras. Lecionei sobre classificadores, sinais relacionais aos desenhos do computador, levava os alunos para passeios fora da escola, depois voltava e fazia a roda da conversa em Libras. Eu também lecionei na turma de primeiro ciclo (primeira série) de alunos surdos na escola bilíngue e percebi que os alunos eram acostumados com o contato diretamente em Libras, eles aprenderam e entenderam rápido.

Também acredito que ainda temos dificuldade na acessibilidade de espaço para inclusão de surdocegos, surdos com deficiência mental, ou outras deficiências. Temos que pensar na possibilidade de inclusão social de surdos e a convivência com seus pares, sejam crianças, jovens, adultos e idosos e também com aqueles que têm algum tipo de deficiência associada à surdez ${ }^{2}$.

\footnotetext{
${ }^{2}$ A surdez, no campo dos Estudos Surdos, no qual se situa este trabalho, entende a surdez como uma diferença linguística e cultural, não como uma deficiência.
} 
Penso que a possibilidade de mudança da área de educação de surdos, no concurso municipal, deva ser efetivada ampliando com mais professores surdos na escola bilíngue. Esta conquista é a convivência do surdo com seus pares na batalha por seus direitos à educação, e se não fomentarmos a formação acadêmica e profissionalização do aluno surdo numa sociedade ouvinte, estaremos a criar exclusões sociais, ao invés de inclusões.

A exclusão profissional e social dos surdos, ainda hoje, confirma que a linguagem pode ser fonte de discriminação e organização social restritiva, mais intensa do que cor, religião ou situação socioeconômica. Entre surdos e ouvintes há grande diferença que os distingue: a linguagem. É necessário, então, que seja difundida e utilizada a Língua de Sinais, língua natural do surdo, dissociada do som e essencialmente visual/gestual. A linguagem interior se expressa por sinais.

Nas entrevistas realizadas todas destacam como importante conquista a criação da escola de educação bilíngue em Porto Alegre. No entanto, existem poucos professores surdos aprovados em concursos públicos, ocasionando assim, um sério problema na qualidade da educação dos estudantes surdos. Faltam professores surdos em geografia, matemática, química ou biologia que possam atender as necessidades da comunidade surda. Assim, apesar de algumas conquistas adquiridas, muito ainda há para se fazer. É indispensável continuar a luta pela cultura surda, pelas políticas surdas e pelas escolas de surdos. Desta forma, necessitamos de mais professores surdos para que possamos proporcionar uma maior qualidade na educação dos surdos para possibilitar uma melhor inserção destes na sociedade.

A escola de inclusão não contempla o sonho. Retira da tomada a energia vital para fluir e canalizar esse sonho e a esperança cai por terra. Simplesmente colocar os surdos entre os ouvintes, sem respeitar as suas características, antes de aprender significados, traduzir o seu mundo interior através da Libras e se sentir capaz de interagir com o ouvinte, é temerário. É também importante assegurar profissionais com o domínio de Libras, que conheçam os caminhos e o tempo da aprendizagem do surdo.

A ligação da escola de surdos e as políticas pedagógicas para surdos, vinculadas ao MEC, precisam entender que as culturas são diferentes e que os alunos surdos necessitam de políticas diferenciadas. As conquistas já alcançadas devem significar a abertura de novos espaços de poder para a comunidade surda a fim de dar continuidade às lutas da comunidade surda, de modo a garantir novas conquistas por uma educação de qualidade e uma inclusão mais efetiva.

O movimento surdo, por sua vez, não pode se acomodar com as conquistas já alcançadas, pois ainda existem muitas coisas que precisam ser feitas para conseguirmos atingir o almejado ideário emancipatório e proporcionar novos significados para a sociedade, sendo que é na educação onde essa problemática deve ser canalizada com a transformação do currículo que reflete o estabelecimento de uma cultura hegemônica. 


\section{Referências}

BRASIL. Relatório sobre a política de linguística de educação bilíngue: língua brasileira de sinais e língua portuguesa. Brasília, DF: MEC/SECADI, 2014. Disponível em: <www.bibliotecadigital.unicamp.br/document/?down=56513>. Acesso em: 08 jun. 2015.

CAPOVILLA, F. C. Carta de Fernando César Capovilla ao MEC sobre educação de surdos. Stella Bortoni, Brasília, DF, 2012a. Disponível em: <http://www. stellabortoni.com.br/index.php/artigos/730-iaata-ii-fiaoaoio-iisaa-iapovilla-ao-mii-sobai-iiuiaiao-ii-suaios>. Acesso em: 10 maio 2016.

Pais de crianças surdas enfrentam o dilema entre a escola especial e a rede regular. Globo News, Rio de Janeiro, nov. 2012b. Disponível em: <https:// www.youtube.com/watch?v=MFgUQLMQluM>. Acesso em: 10 maio 2016.

COSTA, M. V.; SILVEIRA, R. H.; SOMMER, L. H. Estudos culturais, educação e pedagogia. Revista Brasileira de Educação, n. 23, p. 36-61, maio/jun./jul./ago. 2003. Disponível em: <http://www.scielo.br/pdf/rbedu/n23/ n23a03>. Acesso em: 08 jun. 2015.

DETANICO, D. Siglas utilizadas no planejamento do CMET Paulo Freire. CELPCYRO, Porto Alegre, [201-]. Disponível em: <http://www.celpcyro.org.br/joomla/index.php?option=com_content\&view=article\&id=926:siglas-utilizadas-no-planejamento-do-cmet-paulo-freire\&catid=39:acontecencias $>$. Acesso em: 10 maio 2016.
ESCOLA MUNICIPAL DE ENSINO FUNDAMENTAL DE SURDOS BILÍNGUE SALOMÃO WATNICK. História da educação de surdos. Porto Alegre, [200-]. Documentos de Arquivo.

JOVCHELOVITCH, S.; BAUER, M. W. Entrevista narrativa. In: BAUER, M. W.; GASKELL, G. (Ed.). Pesquisa qualitativa com texto, imagem e som: um manual prático. Petrópolis: Editora Vozes, 2002. p. 90-113.

LODI, A. C. B. Educação bilíngue para surdos e inclusão segundo a política nacional de educação especial e o decreto n 5.626/05. Educação e Pesquisa, São Paulo, v. 39, n. 1, p. 49-63, jan./mar. 2013. Disponível em: <http://www.scielo.br/scielo.php?script=sci_arttext\&pid=S1517-97022013000100004>. Aceso em: 08 jun. 2015.

THOMA, A. da S.; KLEIN, M. Experiências educacionais, movimentos e lutas surdas como condições de possibilidade para uma educação de surdos no Brasil. Cadernos de Educação, Pelotas: UFPEL, n. 36, p. 107-131, maio/ ago. 2010. Disponível em: <http://periodicos.ufpel.edu. br/ojs2/index.php/caduc/article/viewFile/1603/1486>. Acesso em: 08 jun. 2015. 